\title{
A reivindicação do cumprimento da lei do piso salarial dos professores: outro modo de não dizer eu
}

\author{
The claim of compliance of the wage floor law of teachers: another way of not to \\ say I
}

\author{
Mara Lucia Martins Rodrigues ${ }^{1}$ \\ Universidade do Estado de Mato Grosso
}

Neuza Benedita da Silva Zattar ${ }^{2}$

Universidade do Estado de Mato Grosso

\begin{abstract}
- RESUMO: Neste trabalho, propomos analisar o funcionamento enunciativo de quem diz (locutor-x), para quem se diz (alocutário-x) num tipo específico de texto, que estamos chamando de texto-reivindicatório. São textos que significam e se significam sóciohistoricamente, considerando a vigência da Lei $n^{\circ}$. 11.738/08, que trata da implantação do piso salarial dos profissionais do magistério público da Educação Básica no Brasil. Os textos-reivindicatórios têm por objetivo exigir ou cobrar publicamente algo de interesse coletivo e, geralmente, são grafados em faixas afixadas nos espaços públicos da cidade, tal como a rua ou conduzidas em passeatas, por exemplo. Partimos da hipótese de que nesses textos ocorre um deslizamento na relação $\mathrm{Eu}$ - tu para a relação Ele - ele, caracterizando-se um outro modo de não dizer eu, estabelecendo-se na cena enunciativa o conflito entre quem diz e para quem é dito. Para a realização deste trabalho nos aportamos teoricamente pelo viés da Semântica do Acontecimento, de Eduardo Guimarães (2002, 2005).
\end{abstract}

- PALAVRAS-CHAVE: Semântica do Acontecimento; Desentendimento; Piso Salarial.

- ABSTRACT: In this work, we propose to analyze the enunciative functioning of who say (announcer-x), to whom it is said (allocator-x) in a specific type of text, which we are calling of text-claim. They are texts that mean and are meaning socio-historically, considering the validity of Law no. $11.738 / 08$, which deals of the implementation of the salary floor of professionals of the Basic Education in Brazil. The texts-claims have objective to demand or publicly to collect something of collective interest and are usually written on strips affixed in public spaces of the city, such as the street or conducted in manifestations, for example. We start from the hypothesis that in these texts occurs a slip in the relation I - You to the relation He - he, characterizing another way of not to say I, establishing in the enunciative scene the conflict between who says and to whom it is said. For the accomplishment of this work we guide us theoretically by the bias of Semantics of the Event, by Eduardo Guimarães (2002, 2005).

- KEYWORDS: Semantics of Event; Misunderstanding; Floor Wage

\section{Introdução}

Interessa-nos, neste trabalho, analisar o funcionamento enunciativo de quem diz, para quem se diz num tipo específico de texto, que estamos chamando de textoreivindicatório. Os textos-reivindicatórios têm por objetivo exigir ou cobrar publicamente algo de interesse coletivo e, geralmente, são grafados em faixas afixadas

\footnotetext{
${ }^{1}$ Mestre em Linguística pela UNEMAT. Doutorado em andamento no Programa de Pós-Graduação Stricto Sensu em Linguística da Universidade do Estado de Mato Grosso, Cáceres. rodriguesmara05@gmail.com

${ }^{2}$ Doutora em Linguística pela UNICAMP. Docente do Programa de Pós-Graduação Stricto Sensu em Linguística da Universidade do Estado de Mato Grosso, Cáceres. neuza.zattar@gmail.com
} 
nos espaços públicos da cidade, tais como a rua e/ou conduzidas em passeatas, por exemplo. Desse modo, analisaremos as cenas enunciativas dos textos das faixas, buscando compreender o funcionamento de quem diz (locutor-x), para quem se diz (alocutário-x), partindo da hipótese de que nesses textos ocorre um deslizamento na relação $E u$ - tu para a relação Ele - ele, estabelecendo-se aí o conflito entre as partes envolvidas.

Os textos reivindicatórios dizem sobre os Profissionais da Educação do Município de Glória D'Oeste que exigem o cumprimento da Lei do Piso Salarial. O tema 'Piso Salarial dos Profissionais da Educação' rememora a Lei no . 11.738, de 16 de julho 2008, que trata da implantação do piso salarial para professores do Brasil, na tentativa de homogeneizar os salários e de acabar com as desigualdades salariais existentes no país. Essa lei funciona como um dispositivo regulador do piso salarial a ser pago aos profissionais do magistério público da Educação Básica em todo o território nacional. Vejamos o que diz o $\S 1^{\circ}$ do artigo $2^{\circ}$ da Lei ${ }^{\circ}$. 11.738/08:

$\S 1^{\circ} \mathrm{O}$ piso salarial profissional nacional é o valor abaixo do qual a União, os Estados, o Distrito Federal e os Municípios não poderão fixar o vencimento inicial das Carreiras do magistério público da educação básica, para a jornada de, no máximo, 40 (quarenta) horas semanais.

Os Estados que pagam abaixo do que determina a lei teve um prazo, "até 31 de dezembro de 2009", para se organizar e igualar os salários dos profissionais. No entanto, os Estados, que ainda não cumprem a lei, questionam junto ao Supremo Tribunal Federal o artigo $5^{\circ}$ e o parágrafo único que definem a forma de cálculo da correção do piso unificado, com o argumento de que a forma de reajuste impede o planejamento tributário dos Estados.

Queremos destacar que um dos governadores propositores da mudança na forma de reajuste dos salários dos professores é o do Rio Grande do Sul, Tarso Genro que, como Ministro do governo Lula, apresentou o projeto de lei do piso salarial, enfrentando, à época, forte resistência dos Estados. Como locutor que diz do lugar social do Ministério da Justiça, o ministro propõe a lei para igualar os salários em todo o país, mas como locutor-governador se opõe à lei, se colocando ao lado daqueles que resistem a cumpri-la. Ou seja, o lugar social de dizer determina o que dizer e como dizer, mostrando que a política de homogeneização dos salários dos professores proposta pelo governo federal é legal enquanto não afeta as prioridades e os recursos dos Estados, pela falha da própria lei, pois, entendemos como Orlandi $(2007$, p. 52) que "os sujeitos e os sentidos não estão completos, já feitos definitivamente, eles se constituem e funcionam sob o modo do entremeio, da relação, da falta, do movimento".

Assim como há Estados descontentes com o que a lei prescreve, há também municípios. Um destes municípios, em que o piso salarial também se encontra abaixo do que é estabelecido pela Lei $n^{\circ}$. 11.738/08, é o de Glória D'Oeste, localizado a 300 $\mathrm{km}$ da capital Cuiabá, na região oeste do estado de Mato Grosso, em que os Profissionais da Educação municipal, filiados ao SINTEP - Sindicato dos Trabalhadores do Ensino Público de Mato Grosso, lutam pelos direitos legais, por meio de manifestações nas ruas da cidade.

A partir do conflito que se instala entre os Profissionais da Educação e o poder público municipal de Glória D’Oeste nos textos-reivindicatórios inscritos nas faixas, propomos examinar à luz da Semântica do Acontecimento, disciplina teórica desenvolvida por Guimarães (2002, 2005), a relação de alocução entre as partes envolvidas. 


\section{A rua como espaço de manifestações}

O profissional da educação, que luta pelo que lhe é assegurado por lei, faz dos espaços públicos da cidade um lugar simbólico para manifestar a luta por seus direitos. Segundo Horta (2001, p. 101), a palavra rua "pode designar [...] acontecimentos, significando também a fusão do espacial e do social". Os sentidos da palavra rua nos dicionários de Língua Portuguesa, conforme Horta (Idem, p. 102), são o "lugar de passagem do cidadão [...]. Depois, passa a ser o lugar de passeio, no qual convive uma diversidade social complexa [...]". Por volta do final do século XIX, "a rua começa a ser nomeada como espaço público, em oposição ao espaço privado (casa / trabalho)" (Ibid), passando a significar o espaço para discussão das questões sociais, políticas e trabalhistas por meio de manifestações e passeatas ao longo da história do Brasil.

Rolnik (2012, p. 26) afirma que "há uma luta cotidiana pela apropriação do espaço urbano", que se constitui desde pequenos movimentos até as grandes manifestações que percorrem os logradouros dos grandes centros do país. Podemos destacar, por exemplo, as manifestações ocorridas no Brasil, em 1984, que tomaram as ruas das principais cidades brasileiras pelas campanhas das Diretas-Já. Momento em que as ruas e avenidas deixaram de ser apenas o cenário da circulação de pedestres e motoristas no dia a dia, para assumir o lugar em que o homem exerce o seu direito.

Oito anos mais tarde, em 1992, as ruas são novamente ocupadas pelo movimento estudantil "Caras-pintadas" que exigia o impeachment do Presidente Fernando Collor, e agora em junho de 2013, as avenidas paulistas e cariocas, principalmente, foram palco de manifestações por um Brasil melhor. Nas situações descritas, a rua é significada como um espaço plural de manifestações políticas que afetam os governantes e definem as decisões a serem tomadas a curto e médio prazo.

Em Glória D’Oeste - MT, no ano de 2012, a Avenida dos Imigrantes, o principal espaço público da cidade, também foi tomada como lugar estratégico para as manifestações dos professores municipais, por um memorável do uso do espaço público urbano para fins de reivindicação. Na avenida, foram afixadas faixas constituídas de enunciados reivindicatórios da classe de profissionais da educação que atuam na cidade, buscando produzir nos representantes do governo municipal os efeitos pretendidos, ou seja, o cumprimento das reivindicações.

\section{Os textos-reivindicatórios: outro modo de NÃO dizer eu}

Os textos-reivindicatórios são compreendidos, neste trabalho, como uma unidade de sentido que integra enunciados no acontecimento de enunciação. Essa integração se dá "pela relação transversal entre elementos diversos e a unidade à qual se reportam" (GUIMARÃES, 2010, p.22). Ou seja, entre o texto e o enunciado estabelecese uma relação de integração que é possível ser analisada pelos procedimentos de reescrituração e de articulação ${ }^{3}$.

Segundo Zattar (2012, p. 08), “a relação entre o que se diz e o interpretável requer, para significar, um retorno a uma parte do que já foi enunciada, pois esse imbricamento é necessário para produzir a futuridade do que se diz". Nesta direção, a temporalidade da enunciação dos textos-reivindicatórios se constitui pelo funcionamento da língua no acontecimento do dizer, que projeta uma futuridade ou possibilidade de novas enunciações, que podem incluir uma tomada de decisão de um dos interlocutores inscritos na enunciação.

\footnotetext{
${ }^{3}$ Sobre os procedimentos de reescrituração e articulação, ver Guimarães, 2010.
} 
Os textos-reivindicatórios se constituem em cenas enunciativas por caracterizar o acesso à palavra de 'quem fala' e para 'quem se fala'. Trata-se de um espaço político por dividir e redividir o dizer que se realiza na/pela língua. As cenas enunciativas constituem-se pela distribuição dos lugares sociais de enunciação (locutor-x) e dos lugares de dizer (enunciador) que se caracterizam como universal, individual, coletivo e genérico. Esse lugar de dizer, de certo modo, é o encobrimento do lugar social que sustenta o Locutor enquanto lugar que se representa no próprio dizer.

Para Guimarães (2018, p. 83), “a alocução é uma relação entre aquele que diz e aquele para quem se diz". Estas relações de alocução nas cenas enunciativas são organizadas pelo agenciamento do falante em Locutor - aquele que diz - e alocutário aquele a quem se diz. De outro lado, temos outra relação, a que se estabelece entre o enunciador (lugar de dizer) e aquilo sobre o que se diz.

Nos textos-reivindicatórios das faixas abaixo, interessa-nos analisar como se dá o funcionamento enunciativo daquele que diz (locutor-x) e para quem se diz (alocutário$\mathrm{x})$, buscando compreender em que medida a relação $E u-T u$ passa à relação Ele - Ele.

Vamos aos textos:

1.

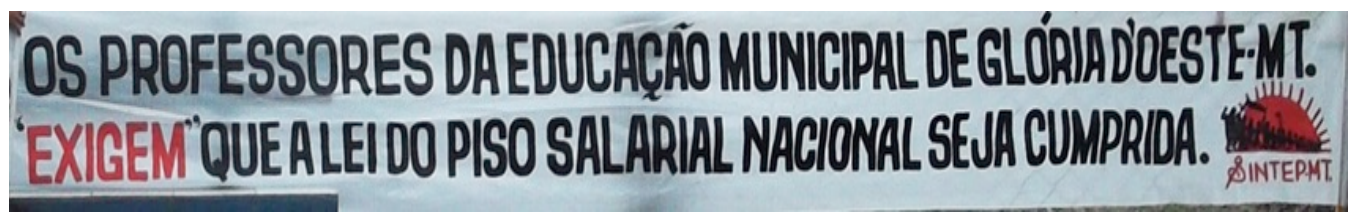

2.

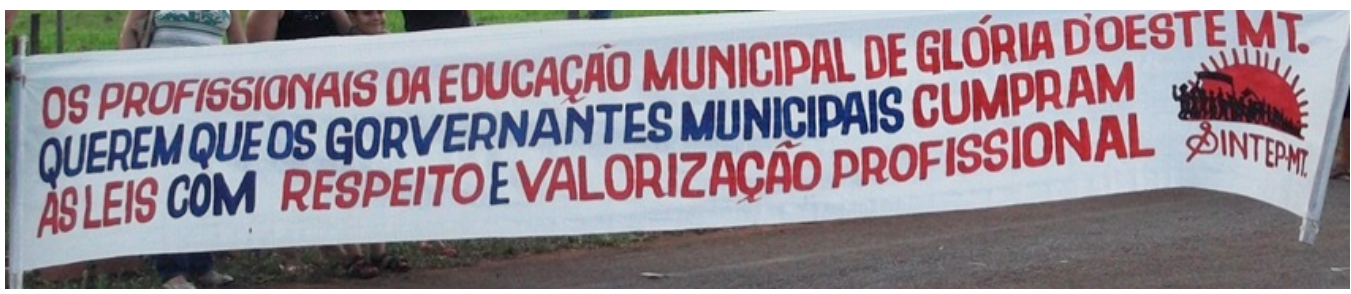

3.

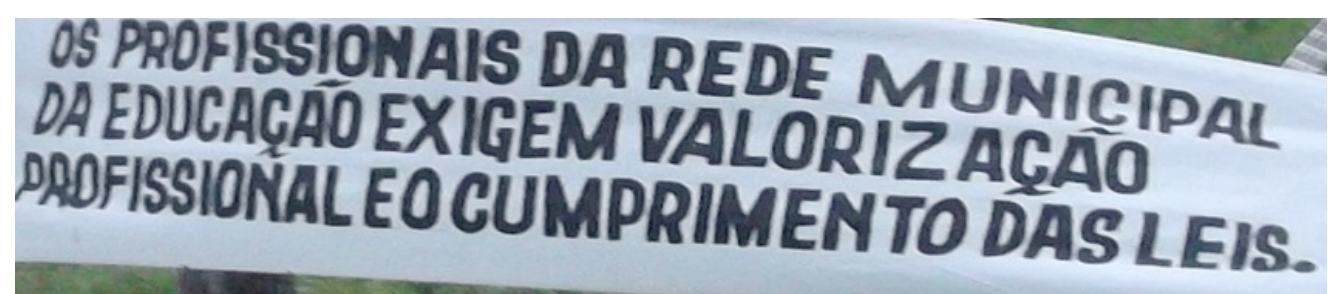

Cada um dos textos-reivindicatórios constitui-se em uma cena enunciativa que, segundo Guimarães (2005, p. 23), "é um espaço particularizado por uma deontologia específica de distribuição dos lugares de enunciação no acontecimento". O locutorempresa ${ }^{4}$ fala em nome dos profissionais da educação, que não assumem o seu lugar social de locutor-professores no enunciado da faixa e, portanto, não se colocam no lugar de quem enuncia.

Para Guimarães (2005) o modo como estes lugares são constituídos se dá pelo funcionamento da língua e, a distribuição dos lugares enunciativos se faz pela

\footnotetext{
${ }^{4}$ Estamos chamando de locutor-empresa aquele responsável pela confecção das faixas.
} 
temporalização que é própria do acontecimento. Deste modo, podemos pensar a cena enunciativa dos textos-reivindicatórios da seguinte forma:

\section{EU DIGO que A diz X}

Neste caso, A representa os professores que, na enunciação, passam a ser o Eles, cujo dizer é representado por X e enunciado pelo locutor-empresa.

Podemos dizer, enunciativamente, que há uma sobreposição de Locutores no enunciado, ou seja, o locutor-empresa diz o que os locutores-professores deveriam dizer, produzindo um efeito polifônico no lugar de quem diz. Temos o funcionamento de um Eu, representado pelo locutor-empresa, que diz que os professores deveriam dizer X aos governantes municipais. Há um deslizamento do Eu para Eles que se dirige a um outro Ele (governante municipal), caracterizando um outro modo de não dizer eu.

Deste modo, temos a seguinte representação:

(1) locutor-empresa diz X para os governantes da cidade.

Desdobrando-se em:

(1.1) A [professores] deveriam dizer X para o alocutário-governantes municipais.

Portanto,

locutor-empresa diz [A (professores municipais) deveriam dizer $\mathrm{X}$ ] para o alocutáriogovernantes da cidade.

Os textos-reivindicatórios das faixas se apresentam por um funcionamento específico, em que os locutores-professores, que deveriam assumir a palavra, não são agenciados em figuras enunciativas e, portanto, não enunciam do lugar social, por não estarem autorizados pela deontologia global da linguagem, fazendo com que esse dizer passa a ser assumido pelo locutor-empresa.

Benveniste (2005, p. 258), em seu artigo Estrutura das relações de pessoa no verbo, diz que o pronome de $3^{\text {a }}$ pessoa não é uma pessoa, ou seja, é a não-pessoa. "É a própria não-pessoa que, estendida e ilimitada pela sua expressão, exprime o conjunto indefinido dos seres não pessoais". Mais adiante, em A natureza dos pronomes, Benveniste (Idem, p. 282) afirma que

\footnotetext{
a "terceira pessoa" representa de fato o membro não marcado da correlação de pessoa. É por isso que não há truísmo em afirmar que a não-pessoa é o único modo de enunciação possível para as instâncias de discurso que não devam remeter a elas mesmas, mas que predicam o processo.
}

Assim, compreendemos que este modo de enunciar, como o que aparecem nos textos reivindicatórios, se dá "como um agenciamento específico da enunciação. Neste embate entre língua e falantes, próprio dos espaços de enunciação, os falantes são tomados por agenciamentos enunciativos, configurados politicamente" (GUIMARÃES, 2005 , p. 22). Trata-se do funcionamento da deontologia da língua que determina modos de dizer para os falantes que se constituem em figuras enunciativas na enunciação das faixas.

Para Guimarães (2005, p. 8) "enunciar é uma prática política” e, desta forma, o sentido pode ser dividido e redividido entre aqueles que têm a posse da palavra. Segundo Machado (2011), pertencer a uma comunidade e ocupar um lugar nesta 
comunidade é o que garante a legibilidade ao que é dito. De outro lado, o acontecimento dos textos-reivindicatórios das faixas é político porque se caracteriza pela contradição entre o locutor-empresa, que reivindica em nome dos profissionais da educação, e o alocutário, que aparece representado por governantes municipais em uma das faixas.

$\mathrm{O}$ não atendimento às reivindicações pode ser compreendido como o desentendimento, tal como formula Rancière:

não é o conflito entre aquele que diz branco e aquele que diz preto. É o conflito entre aquele que diz branco e aquele que diz branco mas não entende a mesma coisa, ou não entende de modo nenhum que o outro diz a mesma coisa com o nome de brancura (1996, p. 11).

Dizendo de outro modo, o desentendimento se instala pelo fato de os professores e o executivo municipal não entenderem da mesma forma os direitos salariais dos profissionais da educação assegurados pela Lei ${ }^{\circ} 11.738 / 08$.

A temporalidade na enunciação dos textos-reivindicatórios se configura pelo presente da enunciação. $O$ acontecimento do dizer reporta ao interpretável (uma projeção de futuridade), ou seja, a possibilidade de os profissionais da educação terem o direito, garantido pela lei, cumprido/respeitado pelos governantes municipais. Este presente e futuro da enunciação reivindicatória funcionam por um memorável de enunciações já ditas - a existência da lei do piso salarial e o seu não cumprimento em alguns Estados e municípios. As palavras de ordem representadas pelas expressões "seja cumprida" (1), "cumpram as leis" (2) e "cumprimento das leis" (3) significam, pelo memorável da Lei no 11.738/08, que ela seja cumprida também em Glória D’Oeste.

$\mathrm{Na}$ enunciação do texto (2), "Os profissionais da educação [...] querem que os governantes municipais [...]", o Locutor instala o alocutário que se constitui por "governantes municipais". Diferentemente de (2), em (1) e (3) mesmo a reivindicação não sendo diretiva, observa-se pela forma verbal "exigem", que o alocutário se mantém, ou seja, mesmo não sendo agenciado, ele está significando, na cena, a autoridade municipal para quem é feita a reivindicação. Este modo particular de organização dos textos-reivindicatórios se caracteriza por um agenciamento específico - quem deve assumir o dizer não o faz - permitindo, pelos modos como o dizer é organizado que o $E u$ deslize para Eles. Parafraseando Dias ${ }^{5}$, isso se dá porque o dizer é afetado por necessidades, proibições e permissões. Tudo o que falamos tem um alcance, que vai além de para quem falamos, abrangendo a comunidade da qual nós fazemos parte.

Enquanto as partes interessadas não entendem igualmente o que diz a Lei $\mathrm{n}^{\circ}$ $11.738 / 08$, o conflito se mantém entre os professores municipais, que se fazem representados por uma outra voz, a do locutor-empresa e por quem não atende às reivindicações, o alocutário-executivo municipal, fazendo dividir e redividir um direito enunciado. Nesta direção, Guimarães (2005, p. 16) diz que

o político está assim sempre dividido pela desmontagem da contradição que o constitui. [...]. Esta desmontagem é o esforço do poder em silenciar a contradição, na busca de um político como ação homogeneizadora que se esgota no administrativo.

Nesta direção, os sentidos dos enunciados que compõem os textosreivindicatórios se constituem sócio-historicamente de modo diferente para os

\footnotetext{
${ }^{5}$ Ver Luiz Francisco Dias (UFMG). Texto (não publicado) trabalhado no grupo de estudos coordenado pelo Professor Taisir Mahmudo Karim, no dia 27/04/2018.
} 
profissionais da educação, representados pela voz do locutor-empresa e para o poder público da cidade de Glória D'Oeste. Esse modo de não compreender da mesma forma o que é reivindicado, produz no acontecimento do dizer o desentendimento.

\section{A reescrituração e articulação nos textos-reivindicatórios}

A reescrituração é redizer insistentemente o já dito. Nos textos-reivindicatórios a reescrituração se dá por substituição de "Os professores" em (1) por "Os profissionais da educação" em (2). Outro ponto a ser considerado é o fato de que nesta reescrituração temos uma relação de hiponímia, ou seja, "professores" é englobado por "profissionais da educação".

A expressão "Os professores da educação municipal de Glória D'Oeste" (1) é reescriturada por substituição por "Os profissionais da educação municipal de Glória D’Oeste" (2) e por "Os profissionais da rede municipal da educação" (3), formando uma rede sinonímica de sentidos. As duas primeiras expressões vêm determinadas pelo locativo "Glória D'Oeste", significando uma diretividade de sentidos para os profissionais daquela cidade, enquanto na terceira expressão ocorre o procedimento de reescrituração por elipse do locativo. Desse modo, a ausência do termo "D'Oeste" pode significar a luta por "valorização profissional e o cumprimento das leis" não somente dos professores do município de Glória, como também de outros municípios brasileiros.

Nas faixas (1), (2) e (3) ocorre o procedimento de articulação entre os elementos "que", "com" e "e". Em "cumpram as leis com respeito $e$ valorização" (2), temos duas articulações. A primeira, por dependência, ou seja, o modo como o cumprimento das leis deve se dar "com" respeito e valorização. A segunda, por coordenação, ou seja, a conjunção "e" articula os elementos "respeito" e "valorização" que são "de mesma natureza e os organiza como se fossem um só da mesma natureza" (GUIMARÃES, p. 51, 2009). Desse modo, trata-se de uma enumeração formada por dois grupos nominais que caracterizam o ato de cumprir as leis pelos governantes municipais.

\section{Palavras finais}

Concluindo, o lugar social dos professores nos textos-reivindicatórios desliza para um Ele (locutor-empresa), assim, os textos-reivindicatórios se configuram num espaço de dizer em que os locutores-professores, por não assumirem a palavra, não se inscrevem nas cenas enunciativas e, esses lugares deixados "vagos" são preenchidos pelo locutor-empresa, autorizado a falar de um determinado modo em uma determinada língua, no nosso caso, a Língua Portuguesa.

A reescrituração presente nos textos-reivindicatórios, afixados na Avenida dos Imigrantes, em Glória D’Oeste, se constituem como um modo de redizer algo já dito. No caso das enunciações analisadas, observa-se a reafirmação da reivindicação dos direitos da categoria dos Profissionais da Educação assegurados na Lei $n^{\circ} 11.738 / 08$. Já o procedimento de articulação traz à tona o encadeamento de grupos nominais que contribuem para a constituição dos sentidos dos textos-reivindicatórios, determinando que o ato de cumprir as leis pelos governantes municipais seja feito com respeito e valorização.

O texto-reivindicatório um tipo de texto que se caracteriza por dizer de um modo e, não de outro, reverberando sentidos que se constituem no/pelo político que permeia toda a história de luta dos professores, que por se considerarem excluídos, lutam, mesmo não assumindo a palavra, pelo cumprimento daquilo que the é 
determinado na lei como um direito e, para isso, vão às ruas manifestar, exigindo o cumprimento da Lei ${ }^{\circ} 11.738 / 08$.

\section{REFERÊNCIAS}

BENVENISTE, Émile. Estrutura das relações de pessoa no verbo. In: Problemas de linguística geral I. Trad. de M. G. Novak e L. Néri. 5. ed. Campinas, SP: Pontes, 2005. A natureza dos pronomes. In: Problemas de linguística geral I. Trad. de M. G. Novak e L. Néri. 5. ed. Campinas, SP: Pontes, 2005.

GUIMARÃES, Eduardo. Semântica do acontecimento: um estudo enunciativo da designação. 2. ed. Campinas, SP: Pontes, 2005.

. A enumeração: funcionamento enunciativo e sentido. Cadernos de Estudos

Linguísticos. Campinas: SP, $\mathrm{n}^{\mathrm{o}} 1$ (ago. 1978). Maio de 2009.

Quando o eu se diz ele: Análise enunciativa de um texto de publicidade.

Revista da Anpoll. Vol. 1, No 29, Niterói - RJ, 2010.

. Dois modos de não dizer eu. In: ORLANDI, Eni P. (Org.). Discurso e

políticas públicas urbanas: a fabricação do consenso. Campinas, Editora RG, 2010.

. Relações apositivas: dinâmica dos lugares de enunciação nas relações de

designação. In: Revista eletrônica Traços de linguagem. V. 2, n. 1, p. 83-94, 2018.

MACHADO, Carolina de Paula. Política e sentidos da palavra preconceito: uma história no pensamento social brasileiro na primeira metade do século XX / Carolina de Paula Machado. Campinas, SP: [s.n.], 2011.

NUNES, José Horta. O espaço urbano: a "rua" e o sentido público. In: ORLANDI, Eni P. Cidade atravessada: os sentidos públicos no espaço urbano. (Org.). Campinas, SP: Pontes, 2001, p. 101-110.

ORLANDI. Eni P. Análise de discurso: Princípios e procedimentos. 7. ed., Campinas, SP: Pontes, 2007.

RANCIÈRE, Jacques. O desentendimento - política e filosofia. Tradução de Ângela Leite Lopes. São Paulo: Editora 34, 1996.

O dissenso. In: NOVAES, Adauto. (Org.). A crise da razão. São Paulo: Companhia das Letras: Brasília, DF: Ministério da Cultura: Rio de Janeiro: Fundação Nacional de Arte, 1996.

ROLNIK, Raquel. O que é cidade. 4. ed. São Paulo, Brasiliense, 2012. (Coleção Primeiros Passos, 203)

ZATTAR, N. B. S.. A corte portuguesa mudou-se ou fugiu para o Brasil. Web-Revista Discursividade: Estudos Linguísticos. V. 01, p. 56-66, 2012.

Recebido em: março de 2018. Aprovado em: junho de 2018.

Como citar este trabalho:

RODRIGUES, M. L. M. ZATTAR, N. B. da S. A reivindicação do cumprimento da lei do piso salarial dos professores: outro modo de não dizer eu. Traços de linguagem, v. 2, n. 2, p. 29-36, 2018. 